\title{
Effects of liraglutide on diastolic function parameters in patients with type 2 diabetes and coronary artery disease: a randomized crossover study
}

\author{
Preman Kumarathurai ${ }^{*}$ (D), Ahmad Sajadieh ${ }^{1}$, Christian Anholm²,3, Ole P. Kristiansen ${ }^{1}$, Steen B. Haugaard ${ }^{2,4}$ (B)
} and Olav W. Nielsen ${ }^{1}$ (1)

\begin{abstract}
Background: Diastolic dysfunction is highly prevalent in patients with type 2 diabetes mellitus (T2DM) and is associated with overweight, glucose dysregulation and coronary artery disease (CAD). The GLP-1 receptor agonist, liraglutide, has shown to induce weight loss and improve metabolic factors, thus modulating factors associated with diastolic dysfunction. We have previously reported the effects of liraglutide on systolic function, and in this current study we explore the effects of liraglutide on diastolic function parameters in patients with stable CAD, preserved left ventricular ejection fraction (LVEF), and newly diagnosed T2DM.

Methods: Thirty subjects were randomized to liraglutide or placebo intervention for $12+12$-weeks in this doubleblind cross-over study. 2D-echocardiography using tissue velocity imaging was used for assessment of diastolic function parameters. Early diastolic filling velocity (E), late atrial filling velocity (A), E-wave deceleration time (EDT) and E/A ratio was assessed from the pulse wave (PW)-Doppler velocity recording of the mitral inflow. Peak early diastolic annular velocities ( $\left.e^{\prime}\right)$ was measured from color tissue doppler images.
\end{abstract}

Results: Liraglutide, when compared to placebo, induced a significant reduction in average $\mathrm{e}^{\prime}$ and lateral $\mathrm{e}^{\prime}$ velocities $(-0.57 \mathrm{~cm} / \mathrm{s}[-1.05$ to -0.08$]$ and $-0.74 \mathrm{~cm} / \mathrm{s}[-1.32$ to -0.15$]$, respectively). Adjusted for the concomitant increase in HR (+6.16 bpm [0.79 to 11.54], the changes were not significant. No significant changes in other diastolic function parameters were observed.

Conclusions: Liraglutide therapy did not improve any diastolic function parameters in subjects with $T 2 D M, C A D$, and preserved LVEF. Instead, a deterioration in e' was observed, which was associated to an increase in heart rate induced by liraglutide therapy.

Trial registration Clinical Trial Registration: http://www.clinicaltrials.gov (unique identifier: NCT01595789) (first submitted May 8, 2012)

Keywords: Diabetes, Diastolic function, Coronary artery disease, Echocardiography, Liraglutide, GLP-1 receptor agonists

*Correspondence: preman.kumarathurai@dadlnet.dk

${ }^{1}$ Department of Cardiology, Copenhagen University Hospital of Bispebjerg, Bispebjerg Bakke 23, 2400 Copenhagen, Denmark Full list of author information is available at the end of the article

\section{Background}

The prevalence of diastolic dysfunction in patients with type 2 diabetes mellitus (T2DM) is up to $75 \%$ and correlates with the degree of glucose dysregulation [1]. The

(c) The Author(s) 2021. This article is licensed under a Creative Commons Attribution 4.0 International License, which permits use, sharing, adaptation, distribution and reproduction in any medium or format, as long as you give appropriate credit to the original author(s) and the source, provide a link to the Creative Commons licence, and indicate if changes were made. The images or other third party material in this article are included in the article's Creative Commons licence, unless indicated otherwise in a credit line to the material. If material is not included in the article's Creative Commons licence and your intended use is not permitted by statutory regulation or exceeds the permitted use, you will need to obtain permission directly from the copyright holder. To view a copy of this licence, visit http://creativeco mmons.org/licenses/by/4.0/. The Creative Commons Public Domain Dedication waiver (http://creativecommons.org/publicdomain/ zero/1.0/) applies to the data made available in this article, unless otherwise stated in a credit line to the data. 
condition is associated with factors such as overweight, hypertension, and coronary artery disease (CAD) [2] . Features of diastolic dysfunction such as impaired left ventricular (LV) relaxation, increased chamber stiffness, and increased LV filling pressure can be assessed noninvasively using 2D echocardiography [3]. Parameters of diastolic function derived from echocardiography have shown to predict mortality and hospitalization for heart failure $[4,5]$.

Glucagon-like peptide 1 (GLP-1) is an incretin hormone that reduces hyperglycemia, improves endothelial function, induce vasodilatory effects on arteries, and in clinical studies shown to reduce cardiovascular events, and improve cardiac function [6]. GLP-1 receptor agonists (RAs) mimic the effects of GLP-1 and is currently a well-established treatment option for T2DM [7]. GlP-1 RAs induce weight loss and improve glucometabolic factors [8], thus modulating risk factors associated with diastolic dysfunction. On this background, it is likely that treatment with GLP-1 RA would improve diastolic function.

In this randomized study, we examined the effect of the GLP-1 receptor agonist liraglutide on parameters of diastolic function in overweight patients with stable CAD, preserved left ventricular ejection fraction (LVEF), and newly diagnosed T2DM.

\section{Methods}

We designed a randomized, double-blind, placebo-controlled 12 plus 12 weeks cross over study with a 2-week washout period. In- and exclusion criteria and the outline of the trial visits have been presented previously $[9$, 10]. In short, we included overweight patients with stable CAD, $\mathrm{LVEF}>40 \%$ and newly diagnosed T2D within 24 months. Patients were recruited through patient files from selected hospitals in Copenhagen (Denmark) from May 2012 to October 2014. Patients on antidiabetic treatment before the study underwent a minimum 2-week washout period before the baseline visit. All subjects underwent 2D echocardiography, blood tests, anthropometric measurements, and blood pressure measurements at the beginning and end of each period (week $0,12,14$, and 26). Subjects, investigators, and all caregivers were blinded to the treatment sequence. Data on systolic function has been published previously [10].

\section{Study drug}

Patients who were on anti-diabetic treatment before the study underwent a minimum 2-week washout period before the first visit. Liraglutide or placebo were titrated in an identical manner in the active and placebo period, respectively: $0.6 \mathrm{mg}$ liraglutide/placebo once daily (o.d.) was increased after 14 days to $1.2 \mathrm{mg}$ o.d and to $1.8 \mathrm{mg}$ o.d. after 28 days. All subjects had a backbone therapy of active metformin that were increased in a similar dose in both periods: $500 \mathrm{mg}$ metformin twice daily was increased to $1000 \mathrm{mg}+500 \mathrm{mg}$ after 14 days and to $1000 \mathrm{mg}$ twice daily after 28 days.

\section{D echocardiography}

The details of echocardiography protocol have been described previously [10]. In short, 2D echocardiography was performed at rest using a M5S transducer (Vivid E9, GE Vingmed Ultrasound, Horten, Norway). LVEF was calculated using the Simpson biplane method. Diastolic function parameters and their respective cut-off values were chosen as recommended in guideline [3]. Early diastolic filling velocity (E), late atrial filling velocity (A), E-wave deceleration time (EDT) and E/A ratio was assessed from the pulse wave (PW)-Doppler velocity recording of the mitral inflow. Peak early diastolic annular velocities $\left(\mathrm{e}^{\prime}\right)$ was measured from color tissue doppler images with sample area placed in the septal, lateral, anterior and inferior parts of the mitral. Measurements was averaged from three beats. Furthermore, heart rate (HR) was measured from the ECG-recording from the echocardiography machine. Four investigators performed the echocardiography examinations (AS, OWN, $\mathrm{OK}$, and $\mathrm{PK}$ ). The off-line echocardiography analyses were performed by one observer $(\mathrm{PK})$ who were blinded to the treatment protocol.

\section{Statistical analysis}

No formal sample size calculation for diastolic function parameters was performed, as the study was primarily powered to detect changes in LVEF [10]. Continuous variables were summarized as the mean $\pm S D$ or medians with interquartile ranges, and categorical variables were summarized as percentages. The per-protocol population was defined as subjects who completed both measurement series in both intervention periods. Treatment effects of liraglutide and placebo were compared by using the paired $t$ test. The association between variables of interest was examined by using linear regression. Chisquare test was used to compare differences in categorical variables between groups. The null hypothesis was rejected for values of $\mathrm{P}$ (two-sided) less than 0.05. All statistical analyses were performed with Stata 13.1 (StataCorp, College Station, Texas, USA).

\section{Results}

In total, 41 subjects were randomly assigned to an intervention in this study. Screening, enrollment, and follow-up of the study population has been described previously [10]. Eleven subjects discontinued the study (2 subjects declined to participate after randomization, 
9 subjects discontinued the study due to serious adverse events, intolerance to medication or other reasons). Thus, 30 subjects were available for the per protocol analyses. See Additional file 1: Figure S1.

The baseline characteristics of the per-protocol study population is shown in Table 1. The study population consisted of $80 \%$ men and had an average age of 63 years. Mean weight was $98.6 \mathrm{~kg}$ corresponding to a

Table 1 Baseline characteristics of the study population

\begin{tabular}{|c|c|}
\hline Characteristics & Total $(n=30)$ \\
\hline \multicolumn{2}{|l|}{ Clinical characteristics } \\
\hline Age, year & $63.1(6.6)$ \\
\hline Male Sex, n (\%) & $24(80)$ \\
\hline Weight, kg & $98.6(18.0)$ \\
\hline $\mathrm{BMl}, \mathrm{kg} / \mathrm{m}^{2}$ & $32.0(5.2)$ \\
\hline Waist, cm & $112.2(10.9)$ \\
\hline Systolic blood pressure, mmHg & $142.7(19.6)$ \\
\hline Diastolic blood pressure, $\mathrm{mmHg}$ & $79.7(10.0)$ \\
\hline Heart rate, bpm & $68.6(10.1)$ \\
\hline \multicolumn{2}{|l|}{ Risk factors } \\
\hline Smoker, n (\%) & $14(36)$ \\
\hline Hypertension, n (\%) & $23(77)$ \\
\hline \multicolumn{2}{|l|}{ Coronary artery disease } \\
\hline Previous Ml, n (\%) & $16(53)$ \\
\hline Previous CABG, n (\%) & $13(43)$ \\
\hline Previous PCl, n (\%) & $16(53)$ \\
\hline Coronary stenosis, medical therapy only, n (\%) & $2(7)$ \\
\hline \multicolumn{2}{|l|}{ Biochemistry } \\
\hline Fasting blood glucose, mmol/l & $6.4(1.4)$ \\
\hline $\mathrm{HbA} 1 \mathrm{C}, \%$ & $6.3(0.5)$ \\
\hline LDL-cholesterol, mmol/l & $2.3(0.7)$ \\
\hline $\mathrm{eGFR}, \mathrm{ml} / \mathrm{min}$ & $78.3(11.5)$ \\
\hline \multicolumn{2}{|l|}{ Medication } \\
\hline Beta blockers, n (\%) & $20(67)$ \\
\hline Calcium antagonists, n (\%) & $15(50)$ \\
\hline ACE-I, ARB, n (\%) & $20(67)$ \\
\hline Statins, n (\%) & $29(97)$ \\
\hline Ivabradine, n (\%) & $1(3)$ \\
\hline Diuretics, n (\%) & $10(33)$ \\
\hline Aspirin, n (\%) & $29(97)$ \\
\hline \multicolumn{2}{|l|}{ Pre-study diabetes medication } \\
\hline Biguanide (metformin), n (\%) & $12(40)$ \\
\hline Sulfonylurea, n (\%) & $1(3.3)$ \\
\hline Diet and lifestyle therapy only, n (\%) & $18(60)$ \\
\hline
\end{tabular}

Data are expressed as the mean (SD) or $\mathrm{n}(\%)$

$A C E-/$ angiotensin converting enzyme inhibitor, $A R B$ angiotensin receptor blocker, $B M I$ body mass index, bpm beats per minute, $C A B G$ coronary artery bypass grafting, $\mathrm{HbA1C}$ glycated hemoglobin, $\mathrm{Ml}$ myocardial infarction, $\mathrm{PCl}$ percutaneous coronary intervention, $L D L$ low-density lipoprotein, eGFR estimated glomerular filtration rate mean BMI of $32 \mathrm{~kg} / \mathrm{m}^{2}$. Pre-study anti-diabetic therapy and cardiovascular medication is shown in Table 1.

Table 2 shows the baseline left ventricular diastolic parameters for the per-protocol population. Signs of diastolic dysfunction occurred in the majority of the subjects: $96.7 \%$ had a reduced e', $30 \%$ had an enlarged left atrium, and $46.7 \%$ had an average $E / \mathrm{e}^{\prime}$ value above 14. However, subjects were well-compensated because the majority had a TR-velocity $\leq 2.8 \mathrm{~m} / \mathrm{s}$ indicating a normal pulmonary systolic pressure. Systolic function parameters have been described previously [10]. The mean LVEF at baseline was 58.9\%. Average s' velocity was $6 \mathrm{~cm} / \mathrm{sec}$ and global longitudinel strain was $16.4 \%$.

Diastolic function parameters before and after intervention are shown in Table 3 . A significant reduction in average e' and lateral e' velocities was observed after 12 weeks of liraglutide treatment as compared with placebo $(-0.57 \mathrm{~cm} / \mathrm{s} ; \mathrm{p}=0.023)$ and $-0.74 \mathrm{~cm} / \mathrm{s} ; \mathrm{p}=0.016$ respectively).

No significant changes in other diastolic function parameters were observed: average E/e', E/A ratio, Peak E velocity, Peak TR velocity, left atrial volume, deceleration time, septal e' velocity.

\section{Table 2 Baseline diastolic function parameters}

\begin{tabular}{|c|c|}
\hline Parameters & Total $(n=30)$ \\
\hline LVMI, gram/m² & $83.4(23.3)$ \\
\hline $\mathrm{RWT}, \mathrm{cm}$ & $0.32(0.1)$ \\
\hline Left atrial volume index, $\mathrm{ml} / \mathrm{m}^{2}$ & $29.3(8.3)$ \\
\hline E/A ratio & $0.95(0.1)$ \\
\hline Peak E velocity, m/s & $0.8(0.2)$ \\
\hline Deceleration time, ms & $239.22(42.3)$ \\
\hline Average $E / e^{\prime}$ & $15.36(6.4)$ \\
\hline Lateral e'velocity, cm/s & $6.59(2.4)$ \\
\hline Septal e' velocity, cm/s & $5.1(1.4)^{*}$ \\
\hline Peak TR velocity, m/s & $2.2(0.5)^{* *}$ \\
\hline Average $e^{\prime}, \mathrm{cm} / \mathrm{s}$ & $5.7(1.6)$ \\
\hline \multicolumn{2}{|l|}{ Systolic function } \\
\hline LVEF, baseline, \% & $58.9(7.2)$ \\
\hline Average s'velocity, cm/s & $6.0(1.3)$ \\
\hline GLS, \% & $16.4(2.9)$ \\
\hline \multicolumn{2}{|c|}{ Number of subjects with signs of diastolic dysfunction } \\
\hline Average $E / e^{\prime}>14, n(\%)$ & $14(46.7 \%)$ \\
\hline $\begin{array}{l}\text { Lateral } e^{\prime} \text { velocity }<10 \mathrm{~cm} / \mathrm{s} \text { or septal e' veloc- } \\
\quad \text { ity }<7 \mathrm{~cm} / \mathrm{s}, \mathrm{n}(\%)\end{array}$ & $29(96.7 \%)$ \\
\hline Peak TR velocity $>2.8 \mathrm{~m} / \mathrm{s}$ & $2(7.4 \%)^{* *}$ \\
\hline Left atrial volume index $>34 \mathrm{ml} / \mathrm{m}^{2}$ & $9(30 \%)$ \\
\hline
\end{tabular}

Data are expressed as mean (SD) or $\mathrm{n}(\%)$

LVMI left ventricular mass index, LVEF left ventricular ejection fraction, RWT relative wall thickness

${ }^{*} \mathrm{n}=29 ;{ }^{* *} \mathrm{n}=27$ 
Table 3 Changes in diastolic function parameters

\begin{tabular}{|c|c|c|c|c|c|c|c|c|c|}
\hline & $\begin{array}{l}\text { Before } \\
\text { liraglutide }\end{array}$ & $\begin{array}{l}\text { After } \\
\text { liraglutide }\end{array}$ & $\begin{array}{l}\text { Before } \\
\text { placebo }\end{array}$ & $\begin{array}{l}\text { After } \\
\text { placebo }\end{array}$ & $\begin{array}{l}\mathrm{N} \\
\text { for treatment } \\
\text { effect }\end{array}$ & $\begin{array}{l}\text { Treatment } \\
\text { effect } \\
\text { for liraglutide }\end{array}$ & $\begin{array}{l}\text { Treatment } \\
\text { effect } \\
\text { for placebo }\end{array}$ & $\begin{array}{l}\text { Difference } \\
(95 \% \mathrm{Cl})\end{array}$ & p-value \\
\hline \multicolumn{10}{|c|}{ Diastolic function parameters } \\
\hline $\begin{array}{c}\text { Average } \\
E / e^{\prime}\end{array}$ & $14.53(5.76)$ & $14.23(5.55)$ & $15.28(6.21)$ & $14.5(5.98)$ & 29 & $-0.20(2.61)$ & $-0.85(3.44)$ & $\begin{array}{l}0.65(-0.86 \\
\text { to } 2.16)\end{array}$ & 0.386 \\
\hline $\begin{array}{l}\text { Lateral e' } \\
\text { velocity, } \\
\mathrm{cm} / \mathrm{s}\end{array}$ & $7.02(2.15)$ & $6.62(2.11)$ & $6.52(2.62)$ & $6.85(1.98)$ & 30 & $-0.40(1.29)$ & $0.33(1.55)$ & $\begin{array}{l}-0.74 \\
(-1.32 \text { to } \\
-0.15)\end{array}$ & 0.016 \\
\hline $\begin{array}{l}\text { Septal e' } \\
\text { velocity, } \\
\mathrm{cm} / \mathrm{s}\end{array}$ & $5.34(1.32)$ & $5.01(1.37)$ & $5.24(1.52)$ & $5.3(1.44)$ & 29 & $-0.31(0.94)$ & $-0.03(1.05)$ & $\begin{array}{l}-0.28 \\
(-0.85 \text { to } \\
0.29)\end{array}$ & 0.326 \\
\hline $\begin{array}{l}\text { Average } e^{\prime}, \\
\mathrm{cm} / \mathrm{s}\end{array}$ & $6.11(1.55)$ & $5.62(1.47)$ & $5.76(1.72)$ & $5.84(1.54)$ & 30 & $-0.49(0.96)$ & $0.08(0.95)$ & $\begin{array}{l}-0.57 \\
(-1.05 \text { to } \\
-0.08)\end{array}$ & 0.023 \\
\hline $\begin{array}{l}\text { Peak TR } \\
\text { velocity, } \\
\text { m/s }\end{array}$ & $2.2(0.55)$ & $2.09(0.6)$ & $2.23(0.52)$ & $2.17(0.53)$ & 26 & $-0.06(0.49)$ & $-0.09(0.27)$ & $\begin{array}{l}0.03(-0.15 \\
\text { to } 0.2)\end{array}$ & 0.732 \\
\hline $\begin{array}{l}\text { Left atrial } \\
\text { volume } \\
\text { index, ml/ } \\
\mathrm{m}^{2}\end{array}$ & $30.36(9.04)$ & $26.42(9.34)$ & $29.78(8.14)$ & $26.77(8.88)$ & 30 & $-3.95(5.59)$ & $-3.01(7.9)$ & $\begin{array}{c}-0.94 \\
(-4.76 \text { to } \\
2.89)\end{array}$ & 0.621 \\
\hline \multicolumn{10}{|c|}{ Other measures of diastolic function and heart rate } \\
\hline E/A ratio & $1.06(0.57)$ & $0.89(0.22)$ & $0.94(0.25)$ & $1.02(0.51)$ & 29 & $-0.18(0.51)$ & $0.08(0.33)$ & $\begin{array}{l}-0.26 \\
(-0.55 \text { to } \\
0.03)\end{array}$ & 0.082 \\
\hline $\begin{array}{l}\text { Mitral valve } \\
\text { peak E } \\
\text { velocity, } \\
\mathrm{cm} / \mathrm{s}\end{array}$ & $0.83(0.19)$ & $0.75(0.16)$ & $0.8(0.16)$ & $0.78(0.17)$ & 29 & $-0.08(0.13)$ & $-0.02(0.12)$ & $\begin{array}{l}-0.06 \\
(-0.13 \text { to } \\
0.02)\end{array}$ & 0.142 \\
\hline $\begin{array}{l}\text { Decelera- } \\
\text { tion time, } \\
\text { millisec- } \\
\text { onds }\end{array}$ & $\begin{array}{l}242.55 \\
(49.71)\end{array}$ & $\begin{array}{l}234.03 \\
(50.97)\end{array}$ & $\begin{array}{l}247.95 \\
(48.19)\end{array}$ & $\begin{array}{r}246.83 \\
(61.02)\end{array}$ & 29 & $-9.90(51.06)$ & $0.07(58.8)$ & $\begin{array}{l}-9.96 \\
(-39.78 \text { to } \\
19.85)\end{array}$ & 0.499 \\
\hline $\begin{array}{l}\text { Heart rate, } \\
\text { bpm }\end{array}$ & $67.67(12.59)$ & 74.28 (13.08) & $68.03(11.56)$ & $68.48(9.25)$ & 30 & $6.61(10.63)$ & $0.45(8.12)$ & $\begin{array}{l}6.16(0.79 \text { to } \\
11.54)\end{array}$ & 0.026 \\
\hline
\end{tabular}

Data are expressed as the mean (SD)

A significant increase in baseline HR after liraglutide therapy was observed $(+6.16 \mathrm{bpm}$ [95\% CI 0.79 to 11.54]).

Changes in resting blood pressure and metabolic variables are shown in Additional file 2: Table S1.

\section{Regression analyses}

Liraglutide treatment was significantly associated with the changes in average e' (beta-coefficient -0.57 ; $\mathrm{p}=0.025$ ), but this correlation disappeared when adjusted for the concomitant increase in HR (betacoefficient $-0.48 ; p=0.071)$. Similarly, no significant associations between lateral and septal e' and liraglutide treatment were found before or after adjustment for HR (Table 4).

We did not find any association between changes in average $\mathrm{e}^{\prime}$, lateral $\mathrm{e}^{\prime}$, septal $\mathrm{e}^{\prime}, \mathrm{E} / \mathrm{e}^{\prime}$ ratio and changes in $\mathrm{HR}$, weight, HbA1C, systolic BP and diastolic BP during liraglutide period. During placebo period we only found an association between changes in average $\mathrm{E} / \mathrm{e}^{\prime}$ and changes in HbA1C (Table 5).

\section{Discussion}

In this double-blind, placebo-controlled study, we examined the effect of 12 weeks of liraglutide treatment on diastolic function parameters as assessed by $2 \mathrm{D}$ echocardiography. We demonstrated that liraglutide did not improve any diastolic parameters. Instead, we observed a reduction in $\mathrm{e}^{\prime}$ suggesting a mild worsening of diastolic function, that may be attributed to an increase in HR induced by liraglutide therapy.

Obesity and T2DM are associated with diastolic dysfunction [11]. Accordingly, weight loss and improvement in metabolic factors have shown to improve parameters of diastolic function [12]. The baseline data in our population revealed a high proportion of subjects 
Table 4 Linear regression models showing the association between liraglutide treatment and changes in diastolic parameters

\begin{tabular}{llll}
\hline & $\boldsymbol{\beta}$-coefficient & $\mathbf{9 5 \%} \mathbf{C l}$ & p-value \\
\hline $\begin{array}{l}\text { Dependent variable } \\
\text { Changes in average } \mathrm{e}^{\prime}\end{array}$ & & & \\
$\quad$ Univariate & -0.57 & -1.06 to -0.07 & 0.025 \\
$\quad \begin{array}{l}\text { Adjusted for changes } \\
\text { in HR }\end{array}$ & -0.48 & -0.995 to 0.043 & 0.071 \\
$\begin{array}{l}\text { Changes in lateral e' } \\
\quad \text { Univariate }\end{array}$ & -0.74 & -1.47 to 0.002 & 0.051 \\
$\quad \begin{array}{l}\text { Adjusted for changes } \\
\text { in HR }\end{array}$ & -0.73 & -1.51 to 0.06 & 0.068 \\
$\begin{array}{l}\text { Changes in septal e' } \\
\quad \text { Univariate }\end{array}$ & & & \\
$\quad \begin{array}{l}\text { Adjusted for changes } \\
\text { in HR }\end{array}$ & -0.28 & -0.80 to 0.24 & 0.289 \\
\hline
\end{tabular}

Independent variable: treatment (liraglutide)

$H R$ heart rate

that displayed one or more abnormal diastolic function parameters. However, despite significant weight loss and improvement in glucometabolic parameters during the liraglutide period, we did not find any improvement in diastolic function parameters. Instead, $e^{\prime}$, a commonly used marker for diastolic function deteriorated. It is not clear if this seemingly worse $\mathrm{e}^{\prime}$ represents a true worsening of diastolic function or is a result of the increased heart rate secondary to liraglutide. We observed a significant negative association between liraglutide treatment and average $\mathrm{e}^{\prime}$ in our regression analyses. Furthermore, when adjusting for the HR changes, the association between $\mathrm{e}^{\prime}$ and liraglutide became non-significant suggesting that the increase in resting HR during liraglutide therapy led to a reduced e.'

Previous studies have shown the inverse relation between HR and diastolic function. Esfandiari et al. showed in a small cohort of subjects with and without HF that atrial pacing impaired diastolic function parameters [13]. Burns et al. showed in 15 subjects that accelerated HR by atrial pacing, induced a significant decrease in e' [14]. However, we did not find any direct correlation between changes in HR and changes in average $e^{\prime}$ in our study. Nevertheless, the HR increase associated with liraglutide has been of concern, namely in subjects with heart failure with reduced ejection fraction [15-17]. An increase in death or rehospitalization for heart failure was observed in subjects with T2DM and heart failure with reduced ejection fraction [16]. Whether the adverse events were due to any detrimental effect of liraglutide

Table 5 Regression coefficients $(\beta)$, R-squared values and $p$-values from linear regression analysis

\begin{tabular}{|c|c|c|c|c|c|c|c|}
\hline \multirow[t]{2}{*}{ Dependent variable } & \multirow[t]{2}{*}{ Independent variable } & \multicolumn{3}{|l|}{ Placebo } & \multicolumn{3}{|c|}{ Liraglutide } \\
\hline & & $\beta$ & $\mathrm{R}^{2}$ & p-value & $\beta$ & $\mathrm{R}^{2}$ & p-value \\
\hline$\triangle$ Average $\mathrm{e}^{\prime}$ & $\Delta$ heart rate & -0.012 & 0.010 & 0.602 & -0.016 & 0.033 & 0.339 \\
\hline$\triangle$ Average $\mathrm{e}^{\prime}$ & $\Delta$ weight & 0.054 & 0.022 & 0.437 & $<0.001$ & $<0.001$ & 0.993 \\
\hline$\triangle$ Average $\mathrm{e}^{\prime}$ & $\triangle \mathrm{HbA} 1 \mathrm{C}$ & -0.010 & $<0.001$ & 0.981 & 0.147 & 0.003 & 0.783 \\
\hline$\triangle$ Average $\mathrm{e}^{\prime}$ & $\triangle$ Systolic BP & 0.006 & 0.010 & 0.603 & 0.002 & 0.001 & 0.882 \\
\hline$\triangle$ Average $\mathrm{e}^{\prime}$ & $\triangle$ Diastolic BP & -0.010 & 0.008 & 0.639 & -0.023 & 0.081 & 0.127 \\
\hline Lateral e' velocity & $\Delta$ heart rate & $<0.001$ & $<0.001$ & 0.993 & -0.002 & $<0.001$ & 0.930 \\
\hline Lateral e' velocity & $\Delta$ weight & 0.008 & $<0.001$ & 0.944 & -0.040 & 0.012 & 0.572 \\
\hline Lateral e'velocity & $\triangle \mathrm{HbA} 1 \mathrm{C}$ & -0.002 & $<0.001$ & 0.997 & 0.126 & 0.001 & 0.861 \\
\hline Lateral e' velocity & $\triangle$ Systolic BP & 0.014 & 0.020 & 0.459 & -0.014 & 0.036 & 0.319 \\
\hline Lateral e' velocity & $\triangle$ Diastolic BP & -0.016 & 0.009 & 0.628 & -0.026 & 0.061 & 0.189 \\
\hline Septal e'velocity & $\Delta$ heart rate & -0.029 & 0.044 & 0.277 & -0.023 & 0.070 & 0.167 \\
\hline Septal e' velocity & $\Delta$ weight & 0.111 & 0.074 & 0.154 & 0.021 & 0.006 & 0.685 \\
\hline Septal e' velocity & $\triangle \mathrm{HbA} 1 \mathrm{C}$ & 0.084 & 0.001 & 0.857 & 0.452 & 0.028 & 0.388 \\
\hline Septal e' velocity & $\triangle$ Systolic BP & 0.000 & $<0.001$ & 0.983 & -0.007 & 0.018 & 0.489 \\
\hline Septal e' velocity & $\triangle$ Diastolic BP & -0.015 & 0.017 & 0.502 & -0.025 & 0.107 & 0.084 \\
\hline Average E/e' & $\Delta$ heart rate & -0.063 & 0.023 & 0.423 & -0.061 & 0.054 & 0.225 \\
\hline Average E/e' & $\Delta$ weight & 0.118 & 0.008 & 0.631 & 0.241 & 0.107 & 0.083 \\
\hline Average E/e' & $\triangle \mathrm{HbA} 1 \mathrm{C}$ & 2.889 & 0.135 & 0.046 & -1.072 & 0.020 & 0.461 \\
\hline Average E/e' & $\triangle$ Systolic BP & -0.008 & 0.002 & 0.836 & -0.010 & 0.004 & 0.735 \\
\hline Average E/e' & $\triangle$ Diastolic BP & -0.045 & 0.014 & 0.539 & 0.055 & 0.064 & 0.185 \\
\hline
\end{tabular}

$H b A 1 C$ glycated hemoglobin, $B P$ blood pressure 
on myocardial relaxation or due to HR increase was not assessed in that study.

Effect of GLP-1 RA on diastolic function in previous trials are in line with our present findings. A randomized, placebo-controlled study of 33 patients with T2DM patients showed that liraglutide blunted the effect of supervised training on diastolic function (e'), which in the placebo groups improved [18]. In a randomized openlabel study, patients with T2DM and subclinical heart failure did not improve diastolic function parameters after 18 weeks of liraglutide therapy when compared to glimepiride treatment [19]. In a small study of 23 patients LV filling pressure was improved after liraglutide therapy, but no effect on myocardial relaxation (e) was seen [20]. Exenatide therapy did not improve either exercise capacity or diastolic function in a randomized, placebo-controlled study [21]. The LIVE study examined the effect of liraglutide on LV function in subjects with LVEF $\leq 40 \%$ [15]. A small improvement in $\mathrm{E} / \mathrm{e}^{\prime}$ was indeed observed; however, the authors note that the clinical relevance of these findings was unclear $[15,22]$. In a prospective, observational, non-randomized study, 6 months of liraglutide therapy improved several diastolic function parameters [23]. However, the study was not randomized or blinded and did not have a prober control-group. In a systemic review and network metanalysis no clear signal on e' was found in GLP-1 RA studies [24].

Potential strength and limitations of the study should be mentioned. The use of crossover design reduced the within-patient variation thus granting appropriate power in our study to address the primary endpoints. We did not perform a power calculation with diastolic function parameters as the study was primarily powered to detect changes in LVEF [10]. Furthermore, carry over effects were not assessed. Thus, the data presented here are exploratory analyses and should be regarded as hypothesis-generating. We analyzed only echocardiographic measures of diastolic dysfunction. Thus, any improvement in parameters associated with diastolic dysfunction, such as dyspnea or natriuretic peptides, were not evaluated in this study. The homogeneity of the cohort limits the application of our results to other patient groups such as patients with severe heart failure, patients with longstanding diabetes with poor glycemic control, or patients with severe CAD.

We previously demonstrated that liraglutide did not improve systolic function [10]. Our current findings suggest that liraglutide does not improve diastolic function either. Instead, we observed deterioration of one of the parameters of diastolic function. As previously described, 48-h HR monitoring revealed an increase in HR of $8.1 \mathrm{bpm}$ after liraglutide therapy when compared to placebo [25]. Although, the resting HR during echocardiography described here were of smaller magnitude, our analyses suggest that the increase in HR may explain this deterioration in diastolic function. If so, HRlimiting medications, such as beta-blockers or sinus node inhibitors, in combination with GLP-1 RAs may improve or at least reduce deterioration of diastolic function parameters. Despite our findings suggesting deterioration of diastolic function, it was demonstrated in the LEADER study [7], that liraglutide had an overall beneficial effect on cardiovascular outcome. This may be due to the pleiotropic effect of liraglutide and GLP-1 RAs in general [26].

\section{Conclusions}

In conclusion, our study showed that liraglutide therapy do not improve any diastolic function parameters in subjects with T2DM, CAD, and preserved LVEF. Instead, we observed a deterioration in e' that may be mediated by the HR increase induced by liraglutide therapy.

\section{Supplementary Information}

The online version contains supplementary material available at https://doi. org/10.1186/s12933-020-01205-2.

Additional file 1: Figure S1. Screening, enrollment, and follow-up of the study population.

Additional file 2: Table S1. Effect of liraglutide versus placebo on blood pressure and metabolic variables. Table S2. Regression coefficients ( $\beta$ ), R-squared values and $p$-values from linear regression analysis.

\section{Acknowledgments}

The AddHope2 investigators thank the patients who participated in this study.

\section{Authors' contributions}

AS and SBH conceived and designed the study. PK, CA, OPK, OW and AS acquired the data. PK performed the statistical analyses. PK drafted the manuscript. PK, CA, OW, OPK, SBH and AS analyzed and interpreted the data and revised the manuscript for important intellectual content. All authors read and approved the final manuscript.

\section{Funding}

This study was supported by an unrestricted grant for investigator-initiated studies from Novo Nordisk A/S. Additional funding was provided by The Danish Heart Foundation, The AP Moller Foundation, Department of Internal Medicine Amager Hospital and Clinical Research Centre Hvidovre Hospital, and The Bispebjerg Hospital Research Foundation.

\section{Availability of data and materials}

The data that support the findings of this study are available from the corresponding author upon reasonable request.

\section{Ethics approval and consent to participate}

This study was approved by the Regional Committee on Biomedical Research Ethics of the Capital Region of Denmark and the Danish Medicines Agency. The study was carried out in accordance with the ICH-GCP (International Conference on Harmonization-Good Clinical Practice) standards. Written informed consent was obtained from each subject.

Consent for publication

All authors gave consent for publication. 


\section{Competing interests}

$\mathrm{SBH}$ has received funding of educational and research tasks from Novo Nordisk, Abbott, Eli Lilly, Pfizer, Boehringer-Ingelheim, Bristol-Meyers Squibb and Merck, Sharp \& Dome. OWN has received funding of educational and research tasks from Resmed and participated in advisory boards for Novartis Pharma. PK, CA, OPK and AS have nothing to disclose.

\section{Author details}

${ }^{1}$ Department of Cardiology, Copenhagen University Hospital of Bispebjerg, Bispebjerg Bakke 23, 2400 Copenhagen, Denmark. ${ }^{2}$ Department of Internal Medicine, University Hospital of Amager, Copenhagen, Denmark. ${ }^{3}$ Department of Nephrology and Endocrinolgy, University Hospital of Hillerød, Hillerød, Denmark. ${ }^{4}$ Department of Endocrinology, University Hospital of Bispebjerg, Copenhagen, Denmark.

Received: 11 September 2020 Accepted: 24 December 2020 Published online: 07 January 2021

\section{References}

1. Seferović PM, Petrie MC, Filippatos GS, Anker SD, Rosano G, Bauersachs J, et al. Type 2 diabetes mellitus and heart failure: a position statement from the Heart Failure Association of the European Society of Cardiology. Eur J Heart Fail. 2018;20(5):853-72.

2. Marwick TH. Diabetic heart disease. Heart. 2006;92(3):296-300.

3. Nagueh SF, Smiseth OA, Appleton CP, Byrd BF, Dokainish H, Edvardsen $T$, et al. Recommendations for the evaluation of left ventricular diastolic function by echocardiography: an update from the american society of echocardiography and the European Association of Cardiovascular Imaging. J Am Soc Echocardiogr. 2016;29(4):277-314.

4. Okura H, Kubo T, Asawa K, Toda I, Yoshiyama M, Yoshikawa J, et al. Elevated $\mathrm{E} / \mathrm{E}^{\prime}$ predicts prognosis in congestive heart failure patients with preserved systolic function. Circ J. 2009;73(1):86-91.

5. Nagueh SF. Left ventricular diastolic function: understanding pathophysiology, diagnosis, and prognosis with echocardiography. JACC CardiovasC Imaging. 2020;13(1 Pt 2):228-44.

6. Ussher JR, Drucker DJ. Cardiovascular actions of incretin-based therapies. Circ Res. 2014;114(11):1788-803.

7. Marso SP, Daniels GH, Brown-Frandsen K, Kristensen P, Mann JFE, Nauck MA, et al. Liraglutide and Cardiovascular Outcomes in Type 2 Diabetes. N Engl J Med. 2016;375(4):311-22.

8. Katout M, Zhu H, Rutsky J, Shah P, Brook RD, Zhong J, et al. Effect of GLP-1 mimetics on blood pressure and relationship to weight loss and glycemia lowering: results of a systematic meta-analysis and meta-regression. Am J Hypertens. 2014;27(1):130-9.

9. Anholm C, Kumarathurai P, Klit MS, Kristiansen OP, Nielsen OW, Ladelund $\mathrm{S}$, et al. Adding liraglutide to the backbone therapy of biguanide in patients with coronary artery disease and newly diagnosed type-2 diabetes (the AddHope2 study): a randomised controlled study protocol. BMJ Open. 2014;4(7):e005942.

10. Kumarathurai P, Anholm C, Nielsen OW, Kristiansen OP, Mølvig J, Madsbad $S$, et al. Effects of the glucagon-like peptide-1 receptor agonist liraglutide on systolic function in patients with coronary artery disease and type 2 diabetes: a randomized double-blind placebo-controlled crossover study. Cardiovasc Diabetol. 2016;15(1):105.

11. Shah AS, Khoury PR, Dolan LM, Ippisch HM, Urbina EM, Daniels SR, et al. The effects of obesity and type 2 diabetes mellitus on cardiac structure and function in adolescents and young adults. Diabetologia. 2011;54(4):722-30.

12. Rider OJ, Francis JM, Tyler D, Byrne J, Clarke K, Neubauer S. Effects of weight loss on myocardial energetics and diastolic function in obesity. Int J Cardiovasc Imaging. 2013;29(5):1043-50.

13. Esfandiari S, Fuchs F, Wainstein RV, Chelvanathan A, Mitoff P, Sasson Z, et al. Heart rate-dependent left ventricular diastolic function in patients with and without heart failure. J Card Fail. 2015;21(1):68-75.

14. Burns AT, Connelly KA, La Gerche A, Mooney DJ, Chan J, Maclsaac Al, et al. Effect of heart rate on tissue Doppler measures of diastolic function. Echocardiography. 2007;24(7):697-701.

15. Jorsal A, Kistorp C, Holmager P, Tougaard RS, Nielsen R, Hänselmann A, et al. Effect of liraglutide, a glucagon-like peptide-1 analogue, on left ventricular function in stable chronic heart failure patients with and without diabetes (LIVE)-a multicentre, double-blind, randomised, placebocontrolled trial. Eur J Heart Fail. 2017;19(1):69-77.

16. Margulies KB, Hernandez AF, Redfield MM, Givertz MM, Oliveira GH, Cole $\mathrm{R}$, et al. Effects of liraglutide on clinical stability among patients with advanced heart failure and reduced ejection fraction: a randomized clinical trial. JAMA. 2016:316(5):500-8.

17. Komajda M, Tavazzi L, Francq BG, Böhm M, Borer JS, Ford I, et al. Efficacy and safety of ivabradine in patients with chronic systolic heart failure and diabetes: an analysis from the SHIFT trial. Eur J Heart Fail. 2015;17:1-8.

18. Jørgensen PG, Jensen MT, Mensberg P, Storgaard H, Nyby S, Jensen JS, et al. Effect of exercise combined with glucagon-like peptide-1 receptor agonist treatment on cardiac function: a randomized double-blind placebo-controlled clinical trial. Diabetes Obes Metab. 2017;19(7):1040-4.

19. Nyström T, Santos-Pardo I, Hedberg F, Wardell J, Witt N, Cao Y, et al. Effects on subclinical heart failure in type 2 diabetic subjects on liraglutide treatment vs glimepiride both in combination with metformin: a randomized open parallel-group study. Front Endocrinol (Lausanne). 2017;8:325.

20. Bizino MB, Jazet IM, Westenberg JJM, van Eyk HJ, Paiman EHM, Smit JWA, et al. Effect of liraglutide on cardiac function in patients with type 2 diabetes mellitus: randomized placebo-controlled trial. Cardiovasc Diabetol. 2019;18(1):55.

21. Scalzo RL, Moreau KL, Ozemek C, Herlache L, McMillin S, Gilligan S, et al. Exenatide improves diastolic function and attenuates arterial stiffness but does not alter exercise capacity in individuals with type 2 diabetes. J Diabetes Complications. 2017;31(2):449-55.

22. Liang B, Gu N. Liraglutide in the treatment of heart failure: insight from FIGHT and LIVE. Cardiovasc Diabetol. 2020;19(1):106.

23. Saponaro F, Sonaglioni A, Rossi A, Montefusco L, Lombardo M, Adda G, et al. Improved diastolic function in type 2 diabetes after a six month liraglutide treatment. Diabetes Res Clin Pract. 2016;118:21-8.

24. Zhang D-P, Xu L, Wang L-F, Wang H-J, Jiang F. Effects of antidiabetic drugs on left ventricular function/dysfunction: a systematic review and network meta-analysis. Cardiovasc Diabetol. 2020;19(1):10.

25. Kumarathurai P, Anholm C, Larsen BS, Olsen RH, Madsbad S, Kristiansen $\mathrm{O}$, et al. Effects of liraglutide on heart rate and heart rate variability: $A$ randomized, double-blind, placebo-controlled crossover study. Diabetes Care. 2017;40(1).

26. Drucker DJ. The cardiovascular biology of glucagon-like peptide-1. Cell Metab. 2016:24(1):15-30.

\section{Publisher's Note}

Springer Nature remains neutral with regard to jurisdictional claims in published maps and institutional affiliations. 